Polymer Journal, Vol. 39, No. 9, pp. 975-981 (2007)

(C) 2007 The Society of Polymer Science, Japan

\title{
Synthesis and Properties of Thermoplastic Alternating Copolymers Containing Trehalose and Siloxane Units by Hydrosilylation Reaction
}

\author{
Naozumi Teramoto,$^{\dagger}$ Masaki Unosawa, Shin Matsushima, and Mitsuhiro ShiBata \\ Department of Life and Environmental Sciences, Faculty of Engineering, Chiba Institute of Technology, \\ 2-17-1 Tsudanuma, Narashino 275-0016, Japan
}

(Received March 30, 2007; Accepted June 21, 2007; Published July 31, 2007)

\begin{abstract}
A trehalose-based diallyl compound (I) was synthesized by the acetalization reaction of $\alpha, \alpha$-Dtrehalose with 4-allyloxybenzaldehyde. Alternating copolymers containing trehalose units and siloxane units were synthesized by the hydrosilylation reaction of the diallyl monomer $\mathbf{I}$ and telechelic SiH-containing siloxanes in the presence of Karstedt's catalyst. As the SiH-containing siloxanes, 1,1,3,3,5,5-hexamethyltrisiloxane with the molecular weight of 208 (II) and dimethylsiloxane oligomers with the molecular weights of $c a .600$ (III) and $c a .1000$ (IV) was used. The structure of the obtained copolymers were fully characterized with ${ }^{1} \mathrm{H}-\mathrm{NMR}$ and FT-IR spectroscopy. The weight average molecular weight $\left(M_{\mathrm{w}}\right)$ of the copolymers ranged from 5900 to 50000 (GPC). The copolymer with the highest $M_{\mathrm{w}}$ was obtained by the reaction of $\mathbf{I}$ and $\mathbf{I I I}$ in toluene at $80^{\circ} \mathrm{C}$ for $72 \mathrm{~h}$. All the polymers showed two glass transition temperatures $\left(T_{\mathrm{g}}\right)$, suggesting microphase separation. The lower $T_{\mathrm{g}}$ was around $-110^{\circ} \mathrm{C}$, which did not depend on the length of the siloxane oligomer segment; and the higher $T_{\mathrm{g}}$ was ranging from $152^{\circ} \mathrm{C}$ to $96{ }^{\circ} \mathrm{C}$, which decreased with an increase in the length of the siloxane oligomer segment. [doi:10.1295/polymj.PJ2006279]

KEY WORDS Trehalose / Siloxane / Hydrosilylation / Thermal Properties /
\end{abstract}

Worldwide potential demands for replacing petroleum-derived raw materials by renewable resources in chemical industry are quite significant from the social and environmental viewpoints. ${ }^{1} \alpha, \alpha$-D-Trehalose is a symmetrical disaccharide found in many living organisms, including mushroom, insects, and yeasts. ${ }^{2}$ Trehalose has a non-reducing character and relatively stable toward acid and heat compared to other sugars. Recently, Hayashibara Co. Ltd developed a low-cost manufacturing process of $\alpha, \alpha$-D-trehalose from starch via enzymatic reactions. ${ }^{2}$ In this view, trehalose is one of promising monomers based on renewable resources for the production of linear polymers. ${ }^{3-6}$ We had already established a facile synthetic strategy to prepare trehalose-based linear polymers using the regioselective reaction of 4,6,4', $6^{\prime}$ hydroxyl groups of $\alpha, \alpha$-Dtrehalose with terephthalaldehyde bis(dimethylacetal) or terephthalaldehyde. ${ }^{4}$ However, the weight average molecular weight $\left(M_{\mathrm{w}}\right)$ of the obtained polymers was not more than 8500 , probably because of the formation of sterically crowded benzylideneglucopyranoside moieties during the polymerization reaction. In addition, the polymer showed no glass transition temperature up to the decomposition temperature.

Our new strategy in order to improve these drawbacks is composed of the synthesis of a trehalosederived diallyl compound (I) using the regioselective acetalization reaction of $\alpha, \alpha$-D-trehalose with 4-allyloxybenzaldehyde, and subsequent polymerization with flexible $\mathrm{SiH}$-terminated dimethylsiloxane oligomers by use of hydrosilylation reaction (Scheme 1). We expect that thermoplasticity of rigid trehalosebased polymers will be improved by incorporation of the flexible units. While trehalose-based polymers are rigid polymers as reported previously, polydimethylsiloxane, whose $T_{\mathrm{g}}$ is quite low, is not a self-standing polymer and often used as rubber after crosslinking process because of the flexibility of backbones. It is important to obtain a self-standing thermoplastic polymer from the prospective of environmental friendliness and material recycling. There have been many literatures on the synthesis of polymers containing siloxane units by the hydrosilylation reactions. ${ }^{7-16}$ Especially regarding the linear polymers containing siloxane units and carbohydrate units, Henkensmeier et al. recently reported the synthesis of carbohydrate-segmented polydimethylsiloxanes with $M_{\mathrm{w}}$ 9000 by use of diallyl compounds derived from dianhydro-D-sorbitol, glucaric acid, galactaric acid, and Dglucose. ${ }^{16}$ They also reported carbohydrate-segmented polydimethylsiloxanes by polycondensation reaction of $\alpha, \omega$-diaminoalkyl polydimethylsiloxanes with glucaric and galactaric acid derivatives. ${ }^{17}$ The polymer was at least partially degraded by a microbial protease.

The present study describes the synthesis and thermal properties of the copolymers of diallyl monomer (I) and $\mathrm{SiH}$-terminated dimethylsiloxane oligomers

${ }^{\dagger}$ To whom correspondence should be addressed (Tel: +81-47-478-0406, Fax: +81-47-478-0439, E-mail: teramoto-n@sea.it-chiba.ac.jp). 


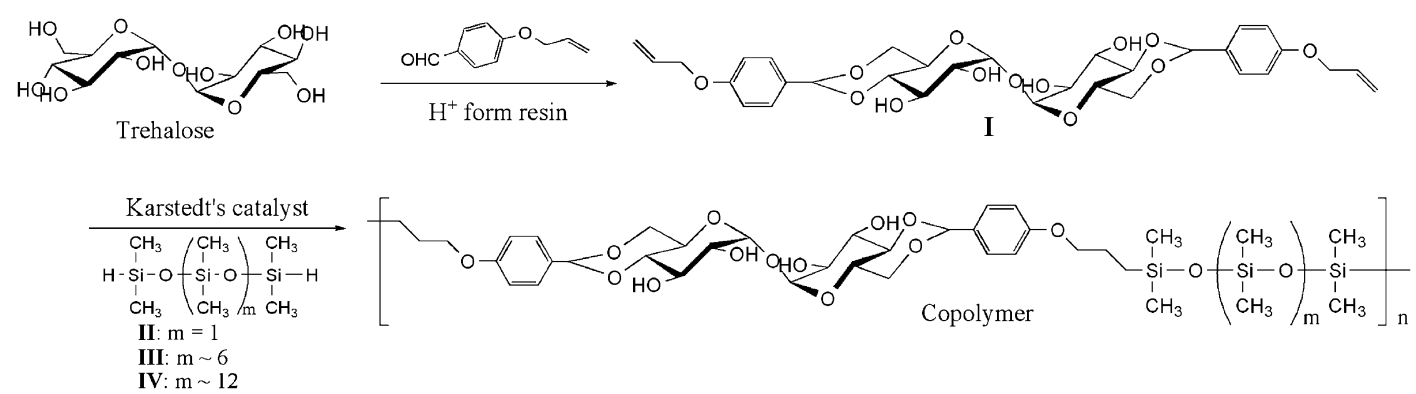

Scheme 1. Synthesis of the copolymers containing trehalose and siloxane units by hydrosilylation reaction.

with different molecular weights. Our attention is focused on the synthesis of high molecular weight copolymers by optimizing the hydrosilylation reaction condition and on the thermal properties of the obtained copolymers.

\section{EXPERIMENTAL}

\section{Materials}

$\alpha, \alpha$-D-Trehalose dihydrate was kindly provided by Hayashibara Co., Ltd. (Japan) and was dehydrated at $130{ }^{\circ} \mathrm{C}$ for $24 \mathrm{~h}$ before use. 4-Allyloxybenzaldehyde, $N, N$-dimethylformamide (DMF; anhydrous), 1,1,3,3,5,5-hexamethyltrisiloxane (II), and a telechelic $\mathrm{SiH}$-terminated dimethylsiloxane oligomer with the number average molecular weight $\left(M_{\mathrm{n}}\right)$ of 580 (III) were used as received from Aldrich Chemical Company (WI). A telechelic SiH-terminated dimethylsiloxane oligomer with the molecular weight of $c a .1000$ (IV), and a platinum 1,3-divinyltetramethyldisiloxane complex (2.1-2.4\% Pt in xylene, Karstedt's catalyst $)^{18}$ were used as received from Gelest, Inc. (PA). The amount of the Si-H groups were determined by the integral values of proton signals in the ${ }^{1} \mathrm{H}$ NMR spectrum. Other anhydrous organic solvents were purchased from Kanto Kagaku (Japan). Amberlyst 15 was purchased from Organo Corp. (Japan). These reagents were used as received.

\section{Synthesis of 4,6,4',6'-O-di-4-allyloxybenzylidene- $\alpha, \alpha$ - D-trehalose (I)}

The acetalization reaction was carried out using a three-neck round-bottom flask equipped with a Dean-Stark trap. To a solution of dried trehalose $(3.42 \mathrm{~g}, 10 \mathrm{mmol})$ in $60 \mathrm{~mL}$ of hot anhydrous DMF were added $6.12 \mathrm{~mL}$ of 4-allyloxybenzaldehyde (40 mmol), $2.66 \mathrm{~g}$ of Amberlyst 15 (12.5 mg-equivalent), and $15 \mathrm{~mL}$ of anhydrous toluene. The solution was constantly stirred and toluene was refluxed at $90^{\circ} \mathrm{C}$ for $24 \mathrm{~h}$ under reduced pressure (220 torr) to remove water azeotropically. After the reaction, the solvent was evaporated and $100 \mathrm{~mL}$ of $0.5 \%$ aqueous sodium hydrogencarbonate solution was added. The precipita- tion was washed with water and dried at room temperature in vacuo for $24 \mathrm{~h}$, dissolved in $10 \mathrm{~mL}$ of 2 methoxyethanol and reprecipitated in $200 \mathrm{~mL}$ of diethylether. The precipitate was dried at room temperature in vacuo for $24 \mathrm{~h}$ to yield a white powder $(3.0 \mathrm{~g}$, $48 \%$ yield). mp. $201^{\circ} \mathrm{C}$. IR ( $\left.\mathrm{KBr}, \mathrm{cm}^{-1}\right): 3400(\mathrm{O}-\mathrm{H})$, 3100, 2950, $2880(\mathrm{C}-\mathrm{H}), 1640$ (allyl C=C), 1620, 1520 (aromatic $\mathrm{C}=\mathrm{C}$ ), 1080, 990 (acetal), 840 (aromatic $\mathrm{CH}$ ). ${ }^{1} \mathrm{H}$ NMR (DMSO- $d_{6}, 400 \mathrm{MHz}, \mathrm{ppm}$ ): $\delta=7.36(\mathrm{~d}, J=8.7 \mathrm{~Hz}, 4 \mathrm{H}$, aryl $), 6.93(\mathrm{~d}, J=8.7$ $\mathrm{Hz}, 4 \mathrm{H}$, aryl), $6.03(\mathrm{~m}, J=5.2 \mathrm{~Hz}, 2 \mathrm{H},-\mathrm{CH}=), 5.51$ $(\mathrm{s}, 2 \mathrm{H}$, acetal $\mathrm{CH}), 5.38(\mathrm{q}, 2 \mathrm{H},-\mathrm{CH}=), 5.26(\mathrm{~m}$, $4 \mathrm{H}, \mathrm{OH}-2,-\mathrm{CH}=), 5.18(\mathrm{~d}, J=5.1 \mathrm{~Hz}, 2 \mathrm{H}, \mathrm{OH}-3)$, $4.93(\mathrm{~d}, J=3.7 \mathrm{~Hz}, 2 \mathrm{H}, H-1), 4.57(\mathrm{~d}, J=5.2 \mathrm{~Hz}$, $4 \mathrm{H}$, allyl $\mathrm{CH}_{2}$ ), 4.05 (m, 4H, H-5, H-6-1), 3.75 (m, $J=5.1 \mathrm{~Hz}, 2 \mathrm{H}, H-3), 3.63(\mathrm{t}, J=9.4 \mathrm{~Hz}, 2 \mathrm{H}, H-6-$ 2), $3.40(\mathrm{~m}, 4 \mathrm{H}, H-2, H-4)$.

\section{General Procedure for Hydrosilylation Polymeriza- tion}

To a solution of $0.315 \mathrm{~g}$ of $\mathbf{I}(0.5 \mathrm{mmol})$ in $4 \mathrm{~mL}$ of anhydrous solvents was added $0.5 \mathrm{mmol}$ of a hydrogen-terminated siloxane oligomer $(0.5 \mathrm{mmol}: 126 \mu \mathrm{l}$ of II, $313 \mu \mathrm{l}$ of III, $565 \mu \mathrm{l}$ of IV) and $0.5 \mu \mathrm{l}$ of a platinum 1,3-divinyltetramethyldisiloxane complex in xylene $(2.1-2.4 \% \mathrm{Pt})$. The solution was stirred for the prescribed time in a reaction vessel sealed under nitrogen using a personal organic synthesizer, ChemiStation PPS-5510 (EYELA, Japan), for controlling the temperature. After the reaction, the solution was added to $100 \mathrm{~mL}$ of hexane, and the resulting precipitate was dried at room temperature for $24 \mathrm{~h}$ to yield a white powder. IR $\left(\mathrm{KBr}, \mathrm{cm}^{-1}\right)$ : polymerization product from the reaction of I with III: $3460(\mathrm{O}-\mathrm{H})$, 3100, 3000, 2950, $2900(\mathrm{C}-\mathrm{H}), 1620,1520$ (aromatic $\mathrm{C}=\mathrm{C}), 1260 \quad(\mathrm{Si}-\mathrm{C}), 1080,990(\mathrm{Si}-\mathrm{O}$, acetal C-O), $840 \mathrm{~cm}^{-1}$ (aromatic C-H). ${ }^{1} \mathrm{H}$ NMR (DMF- $d_{7}, 400$ MHz, ppm): $\delta=7.43(\mathrm{~d}, J=8.6 \mathrm{~Hz}, 4 \mathrm{H}$, aryl $), 6.97$ $(\mathrm{d}, J=8.6 \mathrm{~Hz}, 4 \mathrm{H}$, aryl), $5.58(\mathrm{~s}, 2 \mathrm{H}$, acetal $\mathrm{CH})$, $5.36(\mathrm{q}, 4 \mathrm{H}, \mathrm{OH}-2, \mathrm{OH}-3), 5.12(\mathrm{~d}, J=3.5 \mathrm{~Hz}, 2 \mathrm{H}$, $H-1$ ), 4.19 (m, 4H, H-5, H-6- 1 ), 4.01 (m, 6H, propylene $\mathrm{CH}_{2}, \mathrm{H}-3$ ), 3.72 (t, $\left.J=9.5 \mathrm{~Hz}, 2 \mathrm{H}, H-6-2\right), 3.61$ (m, 2H, H-2), 3.49 (m, overlapping with resonance 


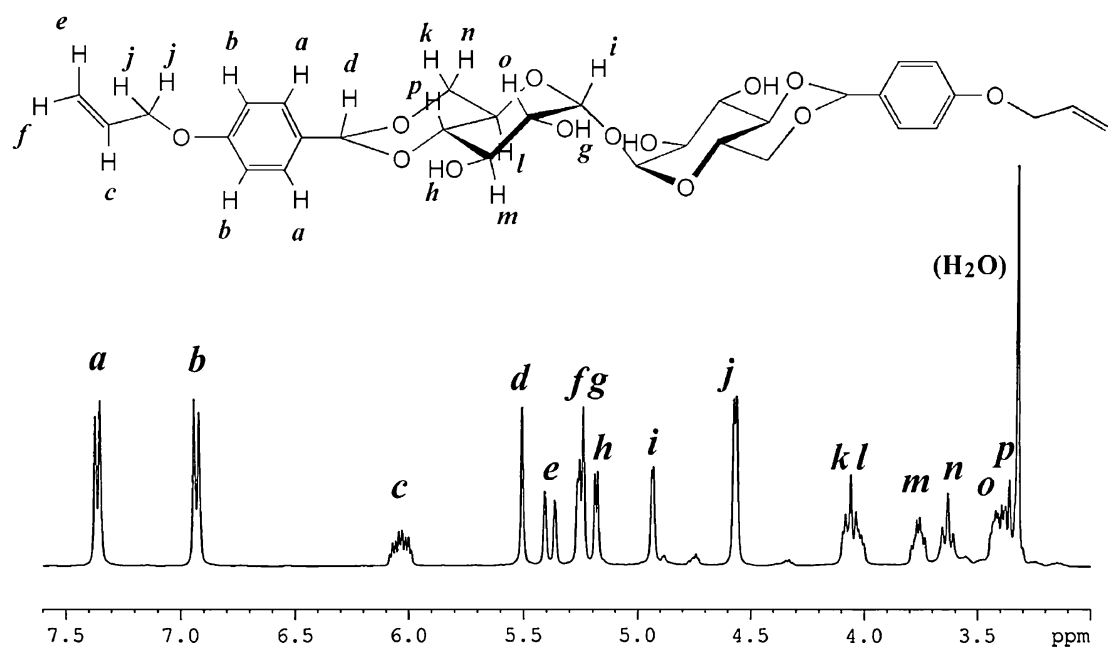

Figure 1. ${ }^{1} \mathrm{H}$ NMR spectrum of 4,6,4',6'-O-di-4-allyloxybenzylidene- $\alpha, \alpha$-D-trehalose (I).

of water, $2 \mathrm{H}, \mathrm{H}-4), 1.85\left(\mathrm{~m}, 4 \mathrm{H}\right.$, propylene $\left.\mathrm{CH}_{2}\right), 0.74$ (t, $J=8.5 \mathrm{~Hz}, 4 \mathrm{H}$, propylene $\left.\mathrm{CH}_{2}\right), 0.15(\mathrm{~m}, 48 \mathrm{H}, \mathrm{Si}-$ $\left.\mathrm{CH}_{3}\right)$.

\section{Characterization}

Fourier transform infrared (FT-IR) spectra were recorded on a Shimadzu FT-IR 8100 by the KBrpellet method. Proton nuclear magnetic resonance $\left({ }^{1} \mathrm{H}\right.$ NMR) spectra were recorded on a Bruker AV$400(400 \mathrm{MHz})$ using DMSO- $d_{6}, \mathrm{DMF}-d_{7}$ or $\mathrm{CDCl}_{3}$ as a solvent. Gel permeation chromatography (GPC) of the polymer products was carried out at $40^{\circ} \mathrm{C}$ on a Shodex GPC analysis apparatus equipped with two SB-806M HQ GPC columns (Showa Denko K. K.) and a reflective index detector. DMF was used as the eluent at a flow rate of $0.5 \mathrm{~mL} / \mathrm{min}$. Polystyrene standards with a narrow distribution of molecular weight $\left(M_{\mathrm{w}}\right.$ : 580-377400) were used for molecular weight calibration. The solubility of polymer products was tested by suspending $5 \mathrm{mg}$ of the polymer powder in $0.5 \mathrm{~mL}$ of solvent. The mixture was sonicated for $1 \mathrm{~min}$ and allowed to stand for $24 \mathrm{~h}$ at room temperature.

Thermogravimetric analysis (TGA) was conducted with a Perkin Elmer thermogravimetric analyzer TGA 7, at a heating rate of $20^{\circ} \mathrm{C} / \mathrm{min}$ under a nitrogen atmosphere. The thermal degradation temperature $\left(T_{\mathrm{d}}\right)$ was defined as the temperature at which the weight of the sample decreased by 5\%. Differential scanning calorimetry (DSC) was performed on a Perkin Elmer differential scanning calorimeter, Diamond DSC, under a helium atmosphere. The sample for DSC was weighed $(\sim 10 \mathrm{mg})$ on a small aluminum pan, followed by sealing the pan. The sample was heated from $-150{ }^{\circ} \mathrm{C}$ to $200^{\circ} \mathrm{C}$ at a heating rate of $20^{\circ} \mathrm{C} / \mathrm{min}$, followed by cooling from $200{ }^{\circ} \mathrm{C}$ to $-150^{\circ} \mathrm{C}$ at $50^{\circ} \mathrm{C} / \mathrm{min}$ and subsequent heating from
$-150{ }^{\circ} \mathrm{C}$ to $200^{\circ} \mathrm{C}$ at $20^{\circ} \mathrm{C} / \mathrm{min}$. The glass transition temperature $\left(T_{\mathrm{g}}\right)$ was determined from the inflection point of the heat capacity curve.

\section{RESULTS AND DISCUSSION}

Synthesis of 4,6,4', $6^{\prime}$-O-di-4-allyloxybenzylidene- $\alpha, \alpha$ D-trehalose (I)

The acetalization reaction of a D-glucopyranosyl group with benzaldehyde is a well-known regioselective reaction often used for protecting 4,6-OH groups. An excess amount of 4-allyloxybenzaldehyde (four times the molar excess of trehalose) was used for completion of the acetalization reaction. Water generated during the reaction was efficiently removed by using a Dean-Stark trap. Sulfonic acid-type cation exchange resin was used as the acid catalyst. The solid catalyst can be removed easily from the reaction solution and is reusable. The ${ }^{1} \mathrm{H}$ NMR spectrum of the dially compound $\mathbf{I}$ is shown in Figure 1. The signals at $7.4 \sim 6.9 \mathrm{ppm}(\mathrm{a}, \mathrm{b})$ were assigned to the aromatic protons of benzylidene groups; the signals at 6.03, 5.26 and $5.18 \mathrm{ppm}(\mathrm{c}, \mathrm{e}, \mathrm{f})$ to the protons around the allyl $\mathrm{C}=\mathrm{C}$ bond. The signal at $4.56 \mathrm{ppm}(\mathrm{j})$ was assigned to the methylene protons of the allyl groups. The signals at $4.93,4.05 \sim 3.40 \mathrm{ppm}(\mathrm{i}, \mathrm{k} \sim \mathrm{p})$ were assigned to the methine and methylene of the trehalose units. Examining the integral values of these signals, the product was found to contain one trehalose unit and two 4-allyloxybenzylidene units. The signal at $5.51 \mathrm{ppm}$ (d) was assigned to the methine proton of the acetal group at the junction of trehalose and benzylidene, strongly suggesting the successful acetalization.

\section{Hydrosilylation Polymerization}

Monomer I was reacted with trisiloxane II in the 


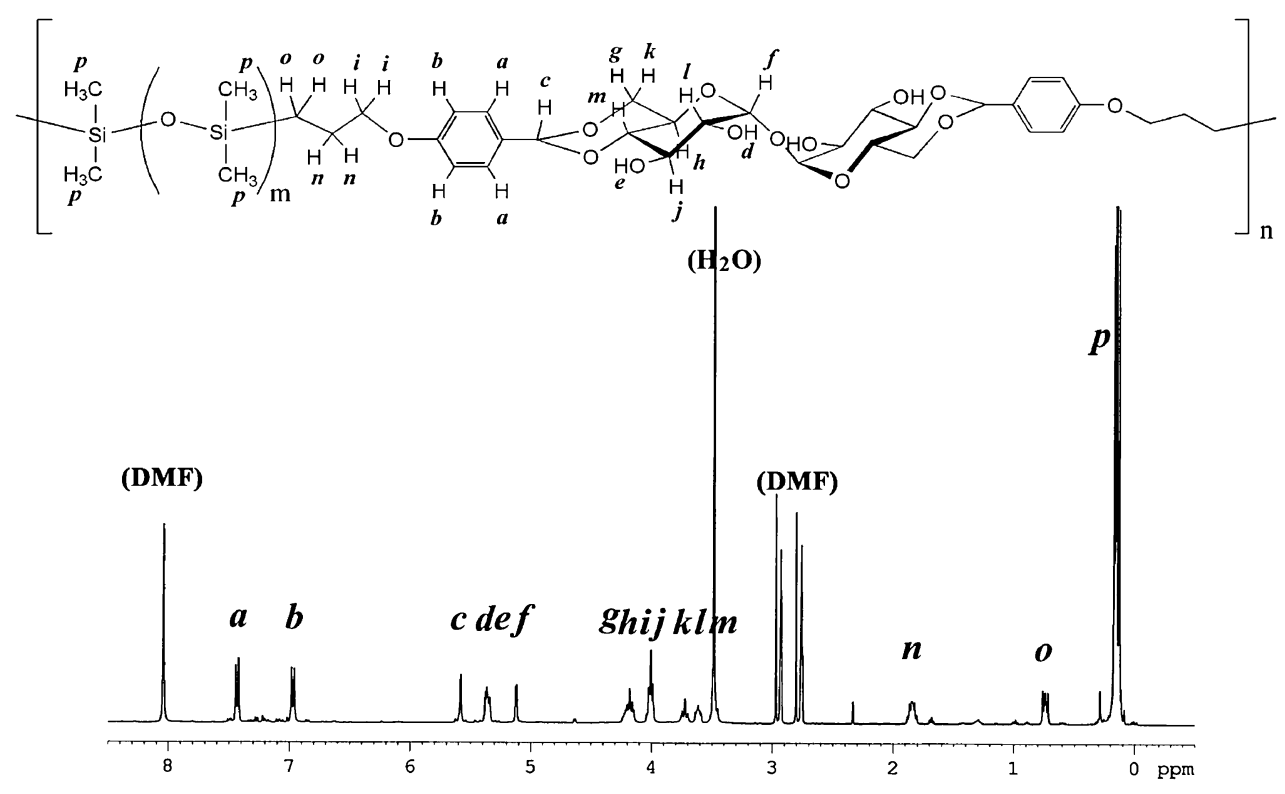

Figure 2. ${ }^{1} \mathrm{H}$ NMR spectrum of the copolymer of I and III in DMF- $d_{7}$.

presence of Karstedt's catalyst, which is an effective hydrosilylation catalyst; ${ }^{18}$ and various solvents such as 2-methoxyethanol, tetrahydrofuran, dichloromethane, acetone and toluene were used as a reaction solvent. When 2-methoxyethanol was used, the hydrosilylation reaction did not proceed because the unexpected reaction of the solvent with II occurred exclusively. ${ }^{19}$ When tetrahydrofuran was used, the molecular weight of the product was lower than 2000 because of a low solubility of monomer $\mathbf{I}$ in the solvent. In case of dichloromethane, although the reaction seemed to proceed smoothly, the molecular weight of the obtained product was not high $\left(M_{\mathrm{n}}\right.$ 2400, $M_{\mathrm{w}}$ 4300); because monomer I did not dissolve in dichloromethane. The use of acetone or toluene gave a successful result.

Figure 2 shows the ${ }^{1} \mathrm{H}$ NMR spectrum of the polymerization product from the reaction of I with III in toluene. Compared to the spectrum of I (Figure 1), the allyl proton signals at $6.03,5.38,5.26$ and 4.63 ppm (c, e, f, and j in Figure 1) diminished significantly, and three methylene proton signals at 4.01, 1.85 and $0.74 \mathrm{ppm}$ (i, $\mathrm{n}$ and $\mathrm{o}$ in Figure 2) and large methyl signals at $0.15 \mathrm{ppm}$ ( $\mathrm{p}$ in Figure 2) appeared. A signal corresponding to the $\mathrm{Si}-\mathrm{H}$ proton at $\sim 4.7 \mathrm{ppm}$ disappeared. These results strongly suggest that the hydrosilylation reaction took place at the allyl groups of $\mathbf{I}$ and $\mathrm{Si}-\mathrm{H}$ groups of III. Examining the integral values of protons from I and those from III in Figure 2, the hydrosilylation reaction almost stoichiometrically occurred. The molecular weights of the polymerization products are summarized in Table I. The product from the reaction of I with III in toluene at $80^{\circ} \mathrm{C}$ for $72 \mathrm{~h}$ had the highest degree of polymerization and molecu- lar weight (DP 9.9; $\left.M_{\mathrm{n}} \sim 12000, M_{\mathrm{w}} \sim 50000\right)$. When the reaction time increased from $24 \mathrm{~h}$ to $72 \mathrm{~h}$, DP decreased in acetone solvent; but in contrast, it slightly increased in toluene solvent. Many unassignable signals were observed in the NMR spectrum of the product from the reaction in acetone for $72 \mathrm{~h}$, indicating that unexpected side reactions occurred in acetone. The $M_{\mathrm{n}}$ of the product obtained from the reaction in toluene at $50^{\circ} \mathrm{C}$ (I and $\left.\mathbf{I I}\right)$ were very low, because unreacted monomers remained in the reaction solution due to insolubility of monomer $\mathbf{I}$ in toluene. It is interesting that the polymerization reaction in toluene at $80^{\circ} \mathrm{C}$ proceeded in good yields with high molecular weight, despite insolubility of monomer I in toluene. At the start of the reaction, the solution was heterogeneous and highly turbid. As the reaction proceeded, the solution became homogeneous and less turbid. It was expected that the molecular weight of the polymerization product would increase when a longer siloxane oligomer reactant was used. In comparison with the products from I and II, molecular weights of the products from I and III or I and IV were high. However, the molecular weights of the products from $\mathbf{I}$ and IV were close to those from I and III. The result may be caused by a decrease in thermal mobility of reactive chain ends. The thermal mobility of chain ends depends on the molecular weight of the elongating polymer chain.

\section{Solubility of Polymers}

Table II shows the results of the solubility test of each polymer in various solvents. The polymer obtained from the reaction of $\mathbf{I}$ and $\mathbf{I I}$ is soluble in relatively polar solvents such as methanol, DMSO, DMF, 
Table I. Hydrosilylation polymerization of I with siloxane oligomers II, III, and IV

\begin{tabular}{|c|c|c|c|c|c|c|c|c|}
\hline \multirow[b]{2}{*}{ Reactant } & \multicolumn{3}{|c|}{ Reaction condition } & \multirow{2}{*}{$\begin{array}{c}\text { Yield } \\
(\%)\end{array}$} & \multicolumn{4}{|c|}{ Molecular weight (GPC) } \\
\hline & $\begin{array}{c}\text { Temperature } \\
\left({ }^{\circ} \mathrm{C}\right)\end{array}$ & $\begin{array}{l}\text { Time } \\
\text { (h) }\end{array}$ & Solvent & & $M_{\mathrm{w}}$ & $M_{\mathrm{n}}$ & $M_{\mathrm{w}} / M_{\mathrm{n}}$ & $\mathrm{DP}^{*}$ \\
\hline I and II & 50 & 24 & acetone & 72 & 13000 & 4900 & 2.7 & 5.8 \\
\hline I and II & 50 & 72 & acetone & 88 & 12000 & 4300 & 2.8 & 5.1 \\
\hline I and II & 50 & 24 & toluene & 70 & 5900 & $900^{\dagger}$ & 6.6 & 1.1 \\
\hline I and II & 50 & 72 & toluene & 79 & 22000 & $2300^{\dagger}$ & 9.6 & 2.7 \\
\hline I and II & 80 & 24 & toluene & 84 & 19000 & 6500 & 2.9 & 7.7 \\
\hline I and II & 80 & 72 & toluene & 83 & 22000 & 6700 & 3.3 & 8.0 \\
\hline I and III & 50 & 24 & acetone & 88 & 36000 & 9300 & 3.9 & 7.7 \\
\hline I and III & 50 & 72 & acetone & 85 & 24000 & 7100 & 3.4 & 5.9 \\
\hline I and III & 80 & 24 & toluene & 88 & 44000 & 12000 & 3.7 & 9.9 \\
\hline I and III & 80 & 72 & toluene & 67 & 50000 & 12000 & 4.2 & 9.9 \\
\hline $\mathbf{I}$ and $\mathbf{I V}$ & 50 & 24 & acetone & 50 & 39000 & 13000 & 3.0 & 7.9 \\
\hline $\mathbf{I}$ and $\mathbf{I V}$ & 50 & 72 & acetone & 53 & 28000 & 9000 & 3.1 & 5.4 \\
\hline $\mathbf{I}$ and $\mathbf{I V}$ & 80 & 24 & toluene & 74 & 40000 & 14000 & 2.9 & 8.5 \\
\hline $\mathbf{I}$ and IV & 80 & 72 & toluene & 70 & 40000 & 14000 & 2.9 & 8.5 \\
\hline
\end{tabular}

${ }^{*}$ Degree of polymerization (DP) was calculated from $M_{\mathrm{n}} \cdot{ }^{\dagger}$ A large monomer peak was observed in the GPC chart.

Table II. Solubility of the copolymers obtained from the reaction of I with siloxane oligomers II, III, and IV (i, insoluble; ps, partially soluble; s, soluble)*

\begin{tabular}{cccc}
\hline \multirow{2}{*}{ Solvent } & \multicolumn{3}{c}{ Copolymer } \\
\cline { 2 - 4 } & I and II & I and III & I and IV \\
\hline Methanol & $\mathrm{ps}$ & $\mathrm{i}$ & $\mathrm{i}$ \\
Acetonitrile & $\mathrm{i}$ & $\mathrm{i}$ & $\mathrm{i}$ \\
DMSO & $\mathrm{s}$ & $\mathrm{s}$ & $\mathrm{i}$ \\
DMF & $\mathrm{s}$ & $\mathrm{s}$ & $\mathrm{s}$ \\
Acetone & $\mathrm{ps}$ & $\mathrm{ps}$ & $\mathrm{ps}$ \\
Dioxane & $\mathrm{s}$ & $\mathrm{s}$ & $\mathrm{ps}$ \\
THF & $\mathrm{s}$ & $\mathrm{s}$ & $\mathrm{i}$ \\
Chloroform & $\mathrm{s}$ & $\mathrm{s}$ & $\mathrm{ps}$ \\
Ethyl acetate & $\mathrm{ps}$ & $\mathrm{s}$ & $\mathrm{ps}$ \\
Diethylether & $\mathrm{i}$ & $\mathrm{i}$ & $\mathrm{ps}$ \\
Toluene & $\mathrm{i}$ & $\mathrm{ps}$ & $\mathrm{ps}$ \\
Hexane & $\mathrm{i}$ & $\mathrm{i}$ & $\mathrm{i}$ \\
\hline
\end{tabular}

*Solubility test was carried out by suspending polymer powder in a solvent by sonication for $1 \mathrm{~min}$ and allowing it to stand for $24 \mathrm{~h}$ at room temperature.

dioxane, and chloroform. On the other hand, the copolymer of I and III is soluble even in less polar solvents such as ethyl acetate and toluene. The copolymer of I and IV was dissolved completely only in DMF among the solvents we have tested. However, the copolymer of I and IV almost dissolved in chloroform, diethylether, ethyl acetate, acetone, toluene, and dioxane. It should be noted that this copolymer is hydrophobic enough and was not dissolved in DMSO. A flexible transparent film can be obtained by casting from the acetone solution of the copolymer of $\mathbf{I}$ and IV (Figure 3).
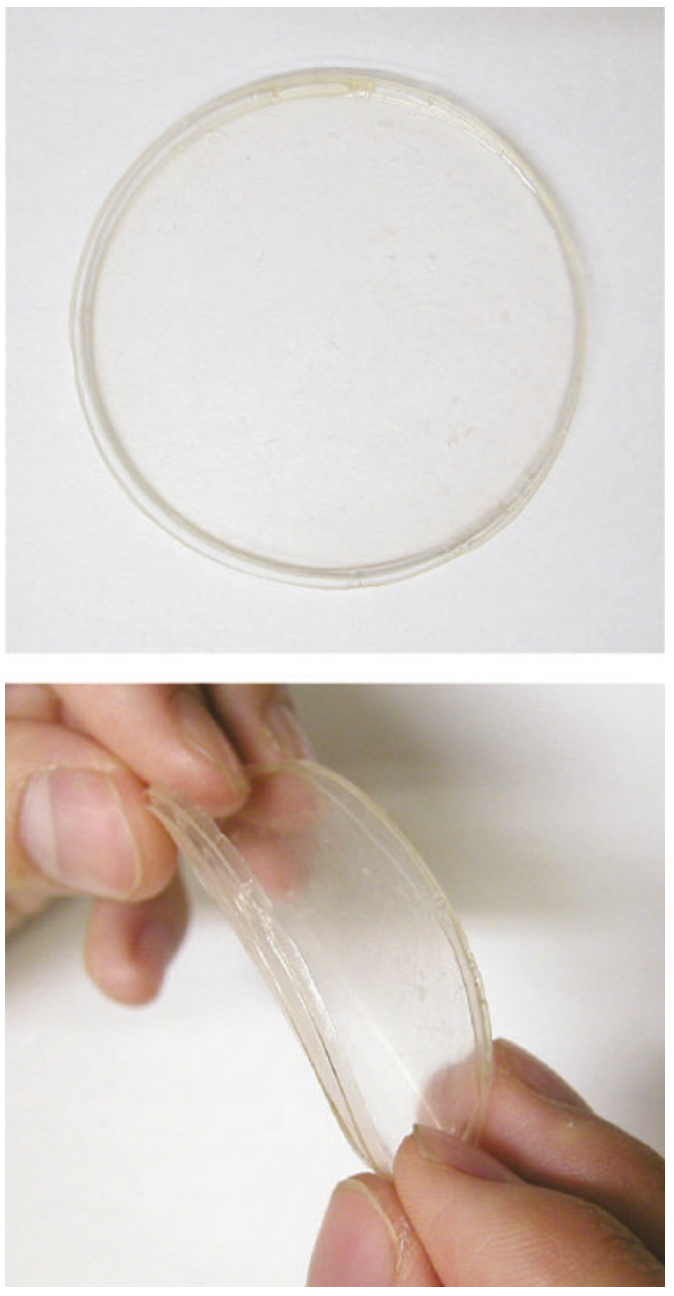

Figure 3. Photographs of the as-cast film of the copolymer of I and IV. 
Table III. Thermal properties of polymers synthesized from I with siloxane oligomers II, III, and IV

\begin{tabular}{cccc}
\hline Copolymer & $T_{\mathrm{g} 1}\left({ }^{\circ} \mathrm{C}\right)^{\dagger}$ & $T_{\mathrm{g} 2}\left({ }^{\circ} \mathrm{C}\right)^{\dagger}$ & $T_{\mathrm{d}}\left({ }^{\circ} \mathrm{C}\right)^{*}$ \\
\hline $\mathbf{I}$ and II & -110 & 152 & 323 \\
I and III & -109 & 122 & 333 \\
I and IV & -110 & 96 & 341 \\
\hline
\end{tabular}

${ }^{\dagger} T_{\mathrm{g}}$ was measured on DSC. Each copolymer has two inflection points: the lower temperature is referred to as $T_{\mathrm{g} 1}$, and the upper as $T_{\mathrm{g} 2} .{ }^{*} T_{\mathrm{d}}$ was measured on TGA and defined as the temperature at which the weight of the sample decreased by $5 \%$.

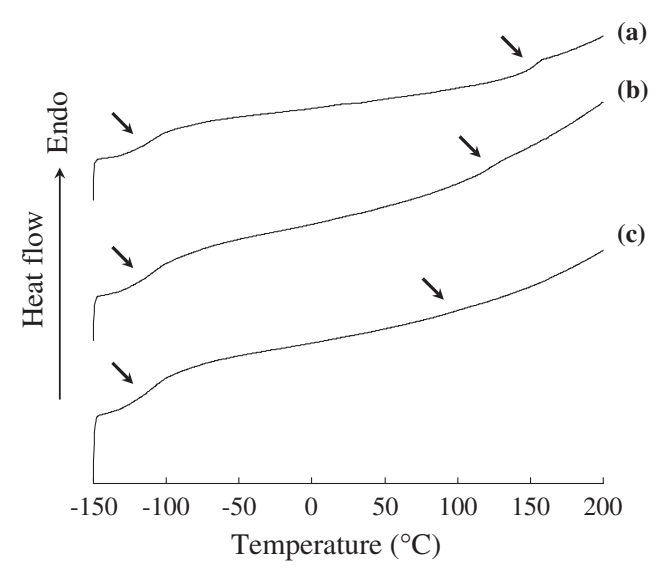

Figure 4. DSC curves of the copolymers of (a) I and II, (b) I and III, and (c) I and IV. Arrow points show the glass transition temperatures.

\section{Thermal Properties of Polymers}

Table III summarizes the thermal degradation temperature $\left(T_{\mathrm{d}}\right)$ and the glass transition temperature $\left(T_{\mathrm{g}}\right)$ of the polymers from the reaction of $\mathbf{I}$ with siloxane oligomers II $\sim$ IV determined by TGA and DSC, respectively. TGA analysis of these polymer products revealed that the $T_{\mathrm{d}}$ of these polymers is over $320^{\circ} \mathrm{C}$ and increased with the length of the siloxane oligomer segments. This thermal stability may be attributed to the stability of the Si-O bond. Considering that the thermal degradation of the copolymers begins at the trehalose units, it is reasonable that the $T_{\mathrm{d}}$ increases with the length of the siloxane oligomer segments, that is, content ratio of siloxane segments to trehalose units. Figure 4 shows the DSC thermograms of the copolymers. Interestingly, each polymer shows two thermal transitions, both corresponding to glass transitions. This result strongly suggests that microphase separation occurred in copolymer samples. The heat capacity gap at the higher transition became less significant by an increase in the length of the siloxane oligomer segments. The lower $T_{\mathrm{g}}\left(T_{\mathrm{g} 1}\right)$, which may correspond to the thermal movement of the silox- ane segments, did not vary by the length of the siloxane oligomer segments; while the upper $T_{\mathrm{g}}\left(T_{\mathrm{g} 2}\right)$, which may correspond to the thermal movement of the dibenzylidene trehalose units, varied by the length of the siloxane oligomer segments. The possible cause of the $T_{\mathrm{g} 2}$ shift is that the thermal movement of the trehalose dibenzylidene units is influenced by the length of adjacent siloxane oligomer segments. This phenomenon seems to be inconsistent with phase separation. To explain the results, we propose the existence of aggregated regions of trehalose units whose size is very small (nano- to subnanometer order) and varies by the length of the siloxane oligomer segments. Hydrogen bonds and $\pi-\pi$ interaction between the trehalose dibenzylidene units may contribute to the aggregation; and these interactions are weakened by an increase in the length of the siloxane oligomer segments because the size of the aggregated regions becomes small and the segment movement in the aggregated regions becomes susceptible to the surrounding flexible regions. No crystal melting peak was observed below $160^{\circ} \mathrm{C}$. The result indicated that the copolymers are amorphous, which is supported by the fact that the copolymer films did not show any crystalline peak in the X-ray diffraction charts. When the liquefying behavior was examined by a microscope with a hot stage, all polymers liquefied gradually at temperatures over $T_{\mathrm{g} 2}$. A transparent film was obtained also by thermal liquefying. The transparent and flexible self-standing film shown in Figure 3 should be attributed to the flexibility of siloxane units and rigidity of dibenzylidene trehalose units, as is expected from $T_{\mathrm{g} 1}$ and $T_{\mathrm{g} 2}$.

\section{CONCLUSIONS}

4,6,4', $6^{\prime}$ - $O$-di-4-allyloxybenzylidene- $\alpha, \alpha$-D-trehalose (I) was synthesized by the acetalization of trehalose with 4-allyloxybenzaldehyde. The hydrosilylation reaction of monomer I with telechelic SiH-terminated siloxane oligomers having various molecular weight in the presence of Karstedt's catalyst in acetone at $50{ }^{\circ} \mathrm{C}$ for $24 \mathrm{~h}$ afforded the alternating copolymers composed of trehalose units and siloxane units in $50-88 \%$ yield. The $M_{\mathrm{w}}$ measured by GPC of the copolymers ranged from 5900 to 50000 . The obtained alternating copolymers were amorphous, as is obvious from no crystalline XRD peak. Each copolymer shows two glass transitions in DSC measurement. The upper $T_{\mathrm{g}}$ decreased with an increase in the length of the siloxane oligomer segment, while the lower $T_{\mathrm{g}}$ did not depend on the length of the siloxane oligomer segment. Transparent and flexible films of the copolymers were obtained not only by solution casting but also by thermal melting. 
Acknowledgment. This study was supported by the Industrial Technology Research Grant Program in '03 from the New Energy and Industrial Technology Development Organization (NEDO) of Japan. This work was also supported by a grant from the Futaba Electronics Memorial Foundation.

\section{REFERENCES}

1. R. Mullin, Chem. Eng. News, 82, 29 (2004).

2. T. Higashiyama, Pure Appl. Chem., 74, 1263 (2002).

3. K. Kurita, N. Masuda, S. Aibe, K. Murakami, S. Ishii, and S. Nishimura, Macromolecules, 27, 7544 (1994).

4. N. Teramoto, Y. Arai, Y. Shibasaki, and M. Shibata, Carbohydr. Polym., 56, 1 (2004).

5. N. Teramoto, Y. Abe, A. Enomoto, D. Watanabe, and M. Shibata, Carbohydr. Polym., 59, 217 (2005).

6. N. Teramoto, Y. Arai, and M. Shibata, Carbohydr. Polym., 64, 78 (2006).

7. P. R. Dvornic, Mater. Sci. Forum, 214, 131 (1996).

8. S. O. Hammouch, G. J. Beinert, and J. E. Herz, Polymer, 37,
3353 (1996).

9. J. Hu and D. Y. Son, Macromolecules, 31, 4645 (1998).

10. S. Andre, F. Guida-Pietrasanta, and B. Boutevin, J. Polym. Sci., Part A: Polym. Chem., 39, 2414 (2001).

11. J. M. Mabry, M. K. Runyon, and W. P. Weber, Macromolecules, 35, 2207 (2002).

12. L. E. Roth, E. M. Vallés, and M. A. Villar, J. Polym. Sci., Part A: Polym. Chem., 41, 1099 (2003).

13. G. David, J. J. Robin, B. Boutevin, and S. André, Eur. Polym. J., 42, 109 (2006).

14. T. M. Gädda and W. P. Weber, J. Polym. Sci., Part A: Polym. Chem., 44, 4825 (2006).

15. K. Loos, G. Jonas, and R. Stadler, Macromol. Chem. Phys., 202, 3210 (2001).

16. D. Henkensmeier, B. C. Abele, A. Candussio, and J. Thiem, J. Polym. Sci., Part A: Polym. Chem., 43, 3814 (2005).

17. D. Henkensmeier, B. C. Abele, A. Candussio, and J. Thiem, Polymer, 45, 7053 (2004).

18. a) B. D. Karstedt, FR. Patent 1548775 (1968).

b) B. D. Karstedt, Chem. Abstr., 71, 91641 (1969).

19. C. Zhang and R. M. Laine, J. Am. Chem. Soc., 122, 6979 (2000). 